\title{
Montserrat and the West Indian Volcanoes*
}

\section{By Sir Gerald Lenox-Conyngham, F.R.S.}

$\mathrm{A}$ BOUT the beginning of 1934, Montserrat began to be troubled by earthquakes and tremors. They became very severe and numerous in May and again in December. In 1935 they were worse still; much damage was done to buildings and naturally a great deal of anxiety was engendered in the minds of the inhabitants. In the autumn of 1935 , the Governor received a petition from the leading members of the population praying that steps should be taken to determine, if possible, whether there was danger of a volcanic eruption.

This anxiety was very natural, for by the inhabitants of that region the terrible events of 1902 are well remembered. In that year on May 7 the Soufrière of St. Vincent burst into eruption and on the following day Mt. Pelé in Martinique did so too. From both of these volcanoes there poured what the French have called a nuée ardente, and what other observers have called the "Great Black Cloud". That from Mt. Pelé swept down upon the town of St. Pierre with such violence and such deadly effect that in a few minutes the whole town and its 30,000 inhabitants were destroyed. In St. Vincent the death roll was not so great because, fortunately, there was no large town in the area over which the cloud flowed.

The island of Montserrat is wholly volcanic. It contains no less than six voleanic cones; of these four lie more or less in a straight line running from north to south and give the island that serrated appearance which is the origin of its name.

The only map of the island is one made by the Hydrographic Department of the Navy in 1867. A recent geological survey of the island, made under great difficulties because of the absence of an accurate topographical map, shows that the

* From a Friday evening discourse delivered at the Royal Institution on March 12. most recent of the volcanic cones is the one called Soufrière Hills or Chance's Mountain, which dominates the town of Plymouth. The island was discovered by Columbus in 1493 and was first colonized by the British in 1632. We know that there has been no volcanic eruption in the island since it has been known to Europe, and from

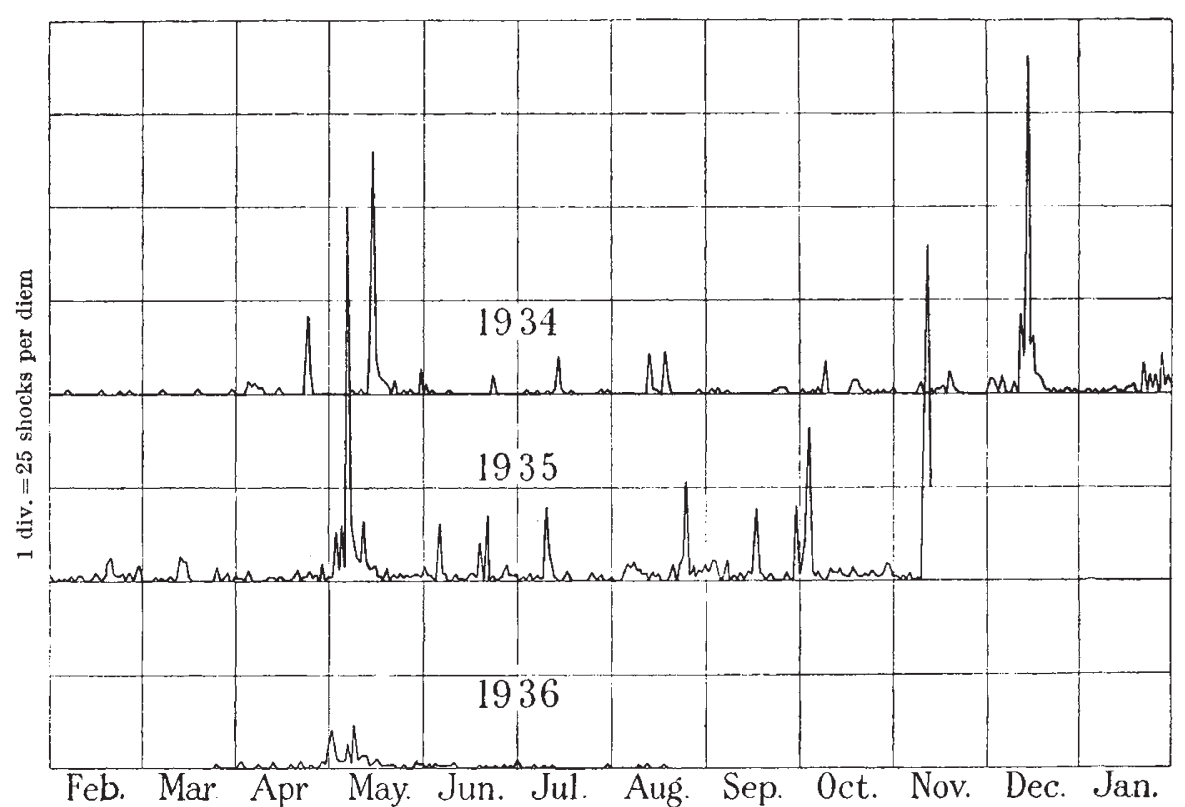

Fig. 1.

the evidence of the erosion that has taken place since the last eruption we may conjecture that that eruption belonged to a much earlier date. But the island has undoubtedly in the past been the scene of repeated volcanic outbursts, and as we know nothing at all of the causes which determine the time and place of an eruption, it would be extremely rash to assert that there will never be another, and certainly the experiences through which Montserrat had passed had been very alarming. Fig. 1 gives the daily number of tremors from February 1934 to November 1935 and again from March to August 1936. As many as 100 were recorded in one day in May 1935, and three other days were nearly as bad, so that the people of Montserrat had ample cause for apprehension.

The result of the petition mentioned above was that the Governor referred the matter to the Colonial Office and that the Colonial Office 
consulted the Council of the Royal Society. It was decided to send out an expedition consisting of a geologist and a physicist to see what they could find out. The geologist selected was Mr. A. G. MacGregor, of the Geological Survey, and the physicist was Dr. C. F. Powell, of the University of Bristol. An invitation was also sent to Dr. T. A. Jaggar of the Volcano Observatory of Hawaii asking him to visit Montserrat and give the members of the expedition the benefit of his great experience. This invitation he accepted. He paid his visit during the months of May and
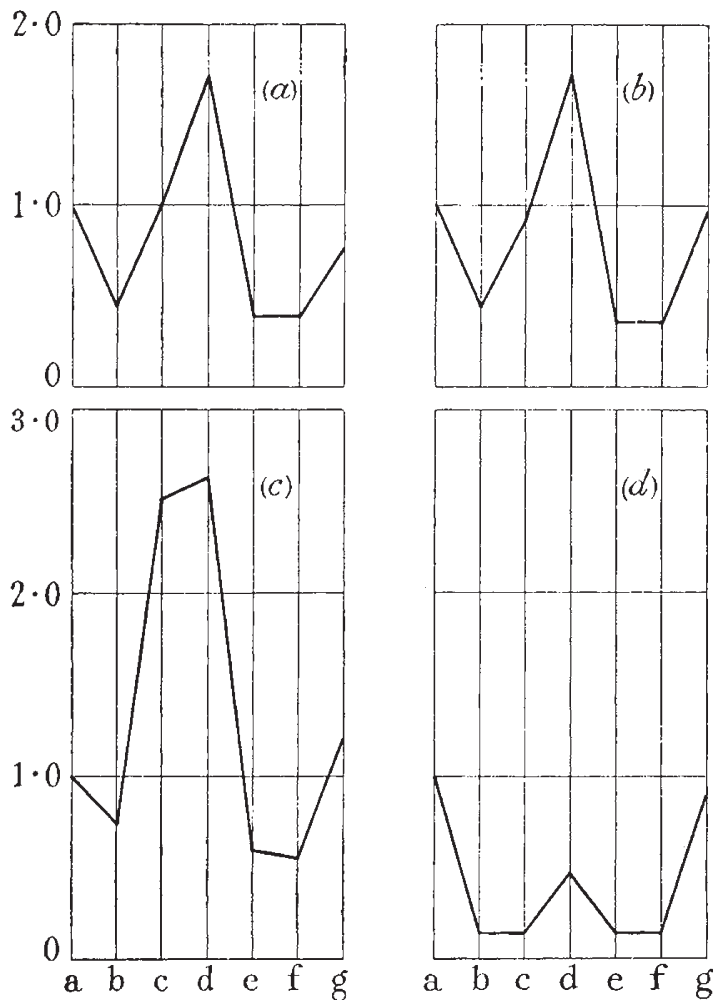

Fig. 2.

June and made a valuable report. The island was also visited several times by Mr. Perret. He is a volcanologist of long experience who has been spending a part of each year since 1929 in Martinique, observing the course of events since the eruption of September 16 of that year. Mr. Perret has made several very helpful reports.

It is worth noting that there is a recurrence of activity in May of each of the years 1934, 1935 and 1936. This may be accidental, for three years do not constitute a long enough period for the establishment of a cycle, but it may be noted that the eruptions of 1902 also began in the month of May, so that there is some evidence of an annual crisis. Unless, however, one can connect a cycle which seems to be indicated by the observations with a physical cause, it is necessary to be careful, and only the most unimpeachable evidence derived from long periods of observation ought to be accepted.

Some careful and trustworthy observers are convinced that a lunar period, similar to that which is to be discerned in the tides, is to be observed in the behaviour of volcanoes, and the action of these tidal forces has sometimes been described as 'trigger action.' That seems an inappropriate term. The essence of a trigger action is that the application of a small force of one kind releases a large force of a different kind. But the action of tidal forces would be to produce a small increase -or diminution-of pressure of the same kind as that to which the crust of the earth is already subjected. There is no question of the release of a different kind of force. To call the effect of such a force as the tidal one a 'last straw' effect is legitimate. It is similar in action to the proverbial last straw. The character of the 'last straw' is its smallness. It does not have any effect unless the load which has already been imposed has very nearly overcome the strength of the 'camel's back'. These tidal forces are small ; they will not produce any visible effect unless the pre-existing stresses are on the point of causing a fracture. If then it can be established that there is a cycle of earthquakes corresponding with the tidal period, it is strong evidence that at all times fracture is very nearly but not quite taking place. In the case of Montserrat, the evidence of an annual cycle is much too weak at present for it to be safe to venture on any inferences.

The Royal Society Expedition left England early in 1936 and was equipped with a number of Jaggar shock-recorders and a Wiechert seismograph. The shock-recorders were designed by Dr. Jaggar, mentioned above. They are simple, satisfactory instruments, not very sensitive but well adapted for recording the sharp, local shocks which were likely to occur. These instruments were in Dr. Powell's charge, and his plan was to erect the shock-recorders at a number of places well distributed over the island so as to obtain information as to the relative severity with which the shocks were felt in the several localities, and thence to deduce the whereabouts of the epicentres.

Dr. Powell made use of his instruments as follows: he noted first that the distribution of amplitude for shocks coming from the same focus should be constant and independent of the individuality of the recording instruments. Thus, taking the amplitude of the movement recorded at a selected station as unity, the amplitude at each of the other stations will be expressed by its ratio to this standard amplitude. If these ratios are plotted, as in Fig. 2, where the ordinates are the ratios and the letters represent the stations, they form a pattern, and it is reasonable to suppose 
that all shocks emanating from the same focus will produce the same pattern.

Then to determine the position of the focus which corresponds to a given pattern, we assume that the amplitude of the waves produced by an earthquake decreases inversely as the distance from the focus. We can estimate the position of the focus corresponding to each of the patterns. The results are shown in the map (Fig. 3). The open circles represent the positions of the epicentres and the shaded ones the positions of the instruments. The epicentres all lie on a belt which crosses the island from south-west to north-east and is rather less than four miles wide.

It is difficult to form any idea of what was going on during the long period of 30 months, during which these frequent tremors occurred. The nature of one of the great tectonic earthquakes, such as that in California in 1906, or in India in 1934, is in general outline clear enough. But these long-continued series of volcanic shocks, with their periods of greater and less activity, are manifestations for which it is hard to account.

Looking at the West Indian region as a whole, there is no apparent system in the way in which eruptions and earthquakes occur. Below is a list of the more important of such events since the beginning of the nineteenth century compiled for the most part by Dr. Jaggar.

\begin{tabular}{|c|c|c|}
\hline 1802 & Mruption & Guadeloupe \\
\hline $1812-14$ & Eruptions & Vincent \\
\hline 1831 & Suhmarine Eruptions & Barbados \\
\hline $1837-34$ & Eruptions & Guadeloupe \\
\hline 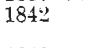 & $\begin{array}{l}\text { Greater Earthquake affecting } \\
\text { many islands }\end{array}$ & \\
\hline 1843 & Submarine Eruption & Guadeloupe \\
\hline I & Gruption of Mont Pelé & Martinique \\
\hline 1867 & $\begin{array}{l}\text { Great sea wave after sub- } \\
\text { marine carthiquake. Felt in } \\
\text { Grenada and elsewhere }\end{array}$ & \\
\hline 1880 & St. Vincent \& & Dominica \\
\hline $1897-99$ & Warthquakes & Montserrat \\
\hline $1902-(11$ & St. Vincent \& & Martinique \\
\hline & Farthquakes & St. Lucia \\
\hline & Earthquake & Jamaica \\
\hline & Farthquake & Puerto Rico \\
\hline & Eruptions Mont Pelé & Martinique \\
\hline & Series of Earthquakes & Nevis \\
\hline-36 & Series of Earthquakes & Montserrat \\
\hline
\end{tabular}

No system or sequence is discernible in these events, but the records are not very complete and they are not based on instrumental observations. If each island were equipped with a recording instrument, there would be a fair prospect of movements being detected which might otherwise escape notice, and these movements might give some clue to the way in which the forces, whatever they are, traverse the region.

There is another line of approach to this problem. It seems to be generally agreed that the Lesser Antilles are oceanic islands which have grown as sabmarine volcanoes from the broad top of a tectonic arc. The islands are therefore only symptoms. The volcanoes have their origin in the tectonic arc, and it is its nature and origin that are of interest to us.
The West Indian island arc is by no means the only one of its kind, and no one who has made the comparison can fail to be struck by the general similarity between the West Indian and the East Indian island arcs. This similarity, however, would not be of much interest if it were not for one special circumstance. It is this. It was a Dutchman, Dr. Vening Meinesz of the Dutch Geodetic Commission, who invented the only

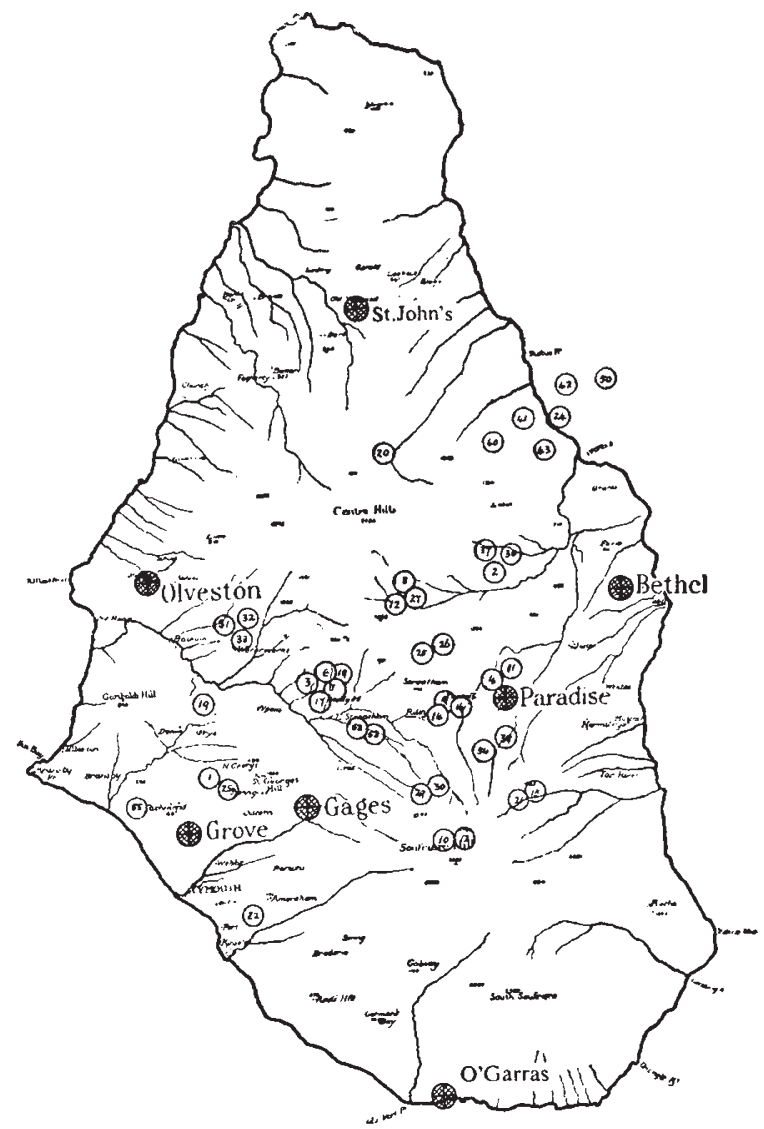

Fig. 3.

successful method, so far, of making determinations of gravity at sex, and these East Indian islands are Dutch possessions. It was not unnatural, therefore, that Dr. Vening Meinesz should see, in the waters surrounding these islands, not only an interesting region for a gravity survey, but also a region in which he would be among his own people and where he could rely on being allowed to call where he liked. His method can only be carried out on a submerged submarine, and as a submarine is essentially a ship of war, foreign harbours cannot be visited without some preliminary negotiation.

Dr. Meinosz made a number of cruises among these islands in the years 1929-30 and determined the value of gravity at more than two hundred places. He discovered, quite to his surprise, that 
there is a continuous belt of negative gravity anomaly on the convex or outer side of the island chain. This line of negatives tells us something about the structure. It shows that along that line the less dense outer layer of the crust has been pressed downwards and has displaced the denser rock below. Dr. Meinesz has drawn a diagram (Fig. 4) to illustrate his conception of the state of things. In the diagram the less dense material of the outer layer of the crust is displacing the denser magma, and it is only by the exertion of continuous pressure that this state of things can be made to persist. If the pressure were withdrawn, gravitational forces would push this root up until it was in floating equilibrium, and the gravity anomalies would disappear. The gravity anomaly then shows that there is a state of strain, that there is abnormal lateral pressure directed across the line of negative anomaly, which runs parallel to the island arc.

It is much to be desired that a similar gravity survey should be made of the West Indian region,

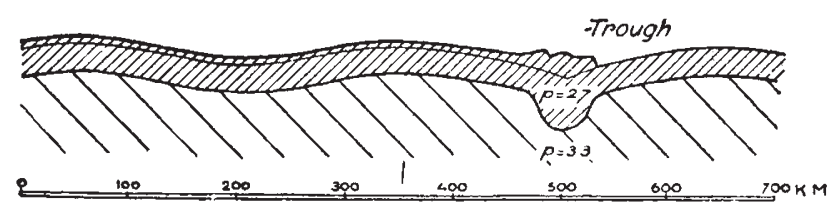

Fig. 4.

and it is very satisfactory to learn that this kas been undertaken by the United States Navy.

There is another feature of these island arcs which I think deserves attention, and that is their curvature. In July 1903 a paper by Mr. Philip Lake entitled "The Circular Form of Mountain Chains" appeared in the Geological Magazine. In it and subsequent papers by the same author, the cause and nature of these arcs were discussed, and what follows is largely derived from them.

Whenever we see an arc of a circle on the surface of a sphere we cannot fail to perceive that it is the intersection of a plane with that surface, and when the arc is marked by a mountain chain or by a festoon of islands-by marks, that is to say, of force of some kind-it is natural to think of the plane as a thrust plane and to imagine that forces acting in that plane have been the cause of the formation of the islands or mountains as the case may be. If this is so, then there must have been some slipping of the matter above the plane on the matter below it. There will be a fault, and the dip of the fault can easily be shown to be equal to the radius of the circular arc.

Mr. Lake examined the arc formed by the Himalayas and suggested that its form is due to the fact that there is a thrust plane at its base. It is easy on a globe to find the position of the centre, or, to speak more correctly, the pole of the arc, and then to measure the distance from the pole to the arc in degrees of great circle. Making this measurement, Mr. Lake found that the radius was $14^{\circ}$, and concluded that this must be the dip of the basal thrust plane. In 1919, Mr. C. S. Middlemiss made the first actual measurements of the dip of the Main Boundary fault of the Himalayas. He found it to be between $12^{\circ}$ and $15^{\circ}$. This Main Boundary Fault is the principal line of separation of the older tertiary rocks of the Himalayas from the younger rocks that lie along the foot of the mountains.

One cannot doubt that the great earthquakes which from time to time cause so much devastation in the Gangetic plain are the result of movement of the newer rocks on the older or of fracture resulting from the pressure of the one upon the other, but we need not expect that those earthquakes will find expression in movement along the visible faults, for the movement is much deeper. Mr. Middlemiss, for example, writing of the great earthquake of April 5, 1905, says that the earthquake was due to "a sudden rupture or release of strain occurring . . . where the strain was specially great owing to resistances to the well established forward march of the over-thrusting foot of the Himalayan range".

It appears, then, that the mountain are is due to the overthrusting of the advancing range: that the real seat of the thrust is deep down under the alluvium, that the form of the arc is determined by what is going on down in those depths and that therefore, since the radius of the arc is $14^{\circ}$, the dip of the plane along which the thrust is taking place should also be $14^{\circ}$. It is probable that there are a number of fault planes parallel to the fundamental one, and since at the place where we can examine the matter we find a dip of $14^{\circ}$, we may reasonably infer that the fundamental thrust plane has this inclination also, which corroborates the evidence given by the radius of the arc.

Until, however, we know the results of the gravity survey made by the U. S. submarine, further conjecture on the West Indian problem would be premature. If by gravity observations we can arrive at some idea of the position of the point at which the front of the overriding rock is in contact with the old overridden rock, and if we know the slope of the plane which divides the one from the other, and if also we can form some estimate of the amount of deformation of the dense magma below by the intrusion of the lighter material which has been forced down into it, we shall arrive at some kind of picture of the structure that lies below these volcanic arcs, and that will at any rate be a step in the right direction. 